\title{
INVENTARISASI SERANGGA DAN TINGKAT KERUSAKAN YANG DITIMBULKAN PADA TEGAKAN JATI (Tectona grandis LINN.F) DI AREAL HUTAN TANAMAN RAKYAT (HTR) NEGERI HILA KABUPATEN MALUKU TENGAH
}

Inventory of insects and levels of damages on teak (Tectona grandis LINN.F) at forest plants Hila State District, Maluku District

\author{
Cornelia M.A Wattimena ${ }^{1}$, Fransina Latumahina ${ }^{2}$, dan N.K Kartikawati ${ }^{3}$ \\ ${ }^{2}$ Kontributor Utama, ${ }^{1}, 2$ Universitas Pattimura Ambon, \\ Jl. Ir. M. Putuhena Kampus Poka, Ambon, Indonesia \\ email penulis korespondensi: fransina.latumahina@yahoo.com \\ ${ }^{3}$ Balai Besar Penelitian dan Pengembangan Bioteknologi dan Pemuliaan Tanaman Hutan, \\ Jl. Palagan Tentara Pelajar KM 15, Purwobinangun, Pakem, Sleman, Yogyakarta, Indonesia
}

Tanggal diterima: 07 Februari 2020, Tanggal direvisi: 18 Februari 2020, Disetujui terbit: 05 Juni 2020

\begin{abstract}
The study aims to determine the types of insects that attack teak plants, diagnose the symptoms of attack and estimate the magnitude and intensity of attacks caused by teak pest. The results found two types of pests that attack teak stands namely Woodhoppers (Valanga nigricornis) and Caterpillars (Hyblaea puera) with moderate damage intensity. Valanga nigricornis measuring 45 - $55 \mathrm{~mm}$ (male) and 15-75 mm (female), has a head, chest, thorax and abdomen, yellowish brown with a dark blue hue on the wings. The rear wing is visible when flying and is red. Caterpillars (Hyblaea puera) are found to be brown with a pair of small yellow stripes on each side, and between two lines are dark brown with a length of $3.5 \mathrm{~cm}$, while the cocoon is dark brownish black, with an average length of 1.4-1. $9 \mathrm{~cm}$, and an average weight of 0.7-1.3 mg. Valanga nigricornis attack area of 29.58\% belong to the category of moderate attack and Hyblaea puera of $23.41 \%$ belonging to the category of mild attack.
\end{abstract}

Keywords: woodhoppers, Valanga nigricornis, caterpillars, Hyblaea puera

\begin{abstract}
ABSTRAK
Penelitian bertujuan untuk mengetahui jenis serangga yang menyerang tanaman jati, mendiagnosa gejala serangan serta mengestimasi besarnya intensitas dan luas serangan yang ditimbulkan akibat serangan hama jati. Hasil penelitian menemukan dua jenis hama yang menyerang tegakan jati yakni belalang kayu (Valanga nigricornis) dan ulat jati (Hyblaea puera) dengan intensitas kerusakan tergolong sedang. Belalang kayu (Valanga nigricornis) berukuran 45 - $55 \mathrm{~mm}$ (jantan) dan 15-75 $\mathrm{mm}$ (betina), memiliki kepala, dada, thorax dan abdomen, berwarna cokelat kekuningan dengan corak warna biru gelap di bagian sayap. Bagian sayap belakang terlihat saat terbang dan berwarna merah. Ulat jati(Hyblaea puera) yang ditemukan berwarna coklat dengan sepasang garis kuning kecil di setiap sisi, dan diantara dua garis berwarna coklat gelap dengan panjang 3,5 cm, sedangkan kepompong berwarna coklat tua kehitam-hitaman, dengan panjang rata-rata 1,4-1,9 $\mathrm{cm}$, dan berat rata-rata 0,7-1,3 mg. Luas serangan Valanga nigricornis sebesar 29,58 \% tergolong dalam kategori terserang sedang dan Hyblaea puera sebesar 23,41\% yang tergolong kategori terserang ringan.
\end{abstract}

Kata kunci: belalang kayu, Valanga nigricornis, ulat jati, Hyblaea puera

\section{PENDAHULUAN}

Hutan rakyat merupakan salah satu model pengelolaan sumber daya alam yang berdasarkan inisiatif masyarakat yang bertujuan untuk menghasilkan kayu atau hasil hutan ikutan lainnya sebagai upaya peningkatan pendapatan dan kesejahteraan masyarakat. Pembangunan Hutan Tanaman Rakyat (HTR) dilakukan oleh masyarakat yang berada di dalam dan atau di sekitar hutan, yang terdiri dari perorangan atau kelompok masyarakat yang diberi ijin pengelolaan hutan (Tjoa, Kastanya, Iskar, Latumahina, \& Aponno, 2020). Sasaran lokasi HTR adalah kawasan hutan produksi yang tidak produktif, tidak dibebani izin/hak lain, letaknya diutamakan dekat dengan industri hasil hutan dan telah ditetapkan 
pencadangannya oleh Menteri Kehutanan. Keberhasilan pembangunan Hutan Tanaman Rakyat (HTR) tidak hanya ditentukan oleh penguasaan dan penerapan teknik silvikultur yang sesuai dan taat azas, tetapi juga dipengaruhi oleh aspek lainnya seperti perlindungan terhadap hama maupun penyakit. Serangan hama dan penyakit dapat menurunkan potensi tegakan baik kualitas maupun kuantitasnya. Kerusakan hutan bukan saja terjadi karena ulah manusia tetapi faktor penyebab lain dari kerusakan yaitu serangan hama. Hama adalah semua binatang yang dapat menimbulkan kerusakan pada tegakan dan hasil hutan sehingga menimbulkan kerugian secara ekonomi (Nietschke, Magarey, Borchert, Calvin, \& Jones, 2007).

Jati merupakan salah satu tanaman tropis yang mempunyai nilai ekonomis yang tinggi, karena kayunya tergolong kayu serbaguna dan merupakan salah satu kayu perdagangan yang memiliki kualitas kayu sangat bagus, sangat disukai dan memiliki permintaan sangat tinggi Hidayat dan Sari (2014) dalam (Pattiwael, 2018). Tanaman jati merupakan salah satu jenis tanaman yang ditanam pada Hutan Tanaman Rakyat (HTR) di Negeri Hila, namun dalam pertumbuhannya sering mengalami gangguan akibat serangan hama maupun penyakit (Latumahina \& Susetya, 2015). Hama yang biasanya menyerang tanaman jati adalah Xyleborus destruens Bldf, Neotermes tectonae Damm. (menyerang batang), Captotermes curvignatus Hciver., Leucopholis rorida F. (menyerang akar), Duomitus ceramicus Wlk., Monochamus rusticator Fab. (menyerang kambium sampai ada xylem), Hiblaea puera Cr., Pyrausta machaeralis Wills (menyerang daun), Phassus damor Morr. (menyerang leher akar) dan bahkan beberapa jenis semut dari Genus Anoplolepis juga menyerang jati (Latumahina et al., 2015).

Oleh sebab itu, untuk mempertinggi persentase hidup tegakan jati pada HTR, maka monitoring terhadap serangan hama perlu dilakukan secara teratur, serta perlu adanya identifikasi agar diketahui secara pasti jenis serangga hama yang menyerang tanaman jati, sehingga langkah - langkah pengendalian akan diambil secara tepat. Penelitian ini bertujuan: untuk mengetahui serangga hama yang menyerang tanaman jati serta intensitas dan luas serangan yang ditimbulkannya.

\section{METODE PENELITIAN}

\section{A. Tempat dan waktu penelitian}

Penelitian dilaksanakan dalam areal Hutan Tanaman Rakyat Negeri Hila, Kabupaten Maluku Tengah, pada Bulan Juni - September 2019.

\section{B. Alat dan bahan}

Alat yang digunakan yaitu botol plastik, kaca pembesar, pinset, phiband, haga, meter roll, tali raffia, cat, teropong monokuler, thermometer, kantong plastik, alat tulis menulis, kamera dan buku kunci determinasi serangga (Latumahina, 2008). Bahan yang digunakan yaitu alkohol $70 \%$ dan tanaman jati (Tectona grandis Linn.f).

\section{Pelaksanaan penelitian}

Pengambilan sampel dilakukan pada areal penelitian yang seluas 1 ha dibagi menjadi 5 blok sampel (secara diagonal) dimana ukuran tiap - tiap blok yakni $20 \times 20 \mathrm{~m} 2$. Pengamatan dilakukan pada setiap blok sampel, meliputi intensitas kerusakan terhadap daun tanaman sampel pada bagian atas, bagian tengah dan bawah dengan sistem arah mata angin (Selatan, Utara, Timur dan Barat).

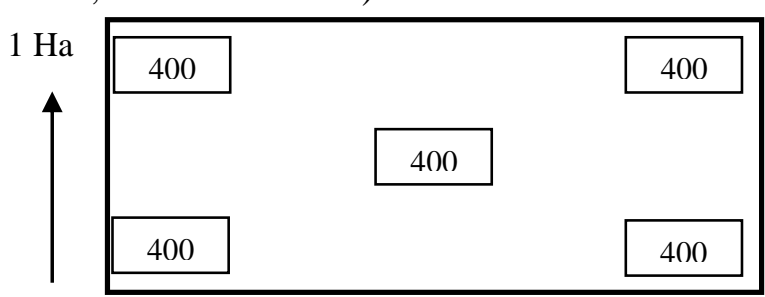

Gambar 1. Areal penelitian

Keterangan

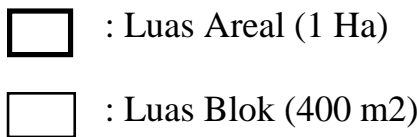




\section{Pengumpulan data}

Data yang diambil meliputi data primer dan data sekunder. Pengumpulan data primer diperoleh dengan pengamatan langsung di lapangan terhadap jenis-jenis hama yang menyerang tanaman jati dan tingkat serangan/kriteria serangan seperti yang dikemukakan oleh (Hariyanto, Jumani, \& Heni, 2014) seperti pada Tabel 1.

Tabel 1. Kriteria dan skor serangan hama

\begin{tabular}{|c|c|c|}
\hline Kriteria & Gejala serangan & Skor \\
\hline Sehat & Tidak ada serangan & 0 \\
\hline Terserang ringan & $\begin{array}{l}\text { Jumlah daun yang terserang dan jumlah serangan pada masing-masing } \\
\text { daun yang terserang sedikit }\end{array}$ & 1 \\
\hline Terserang sedang & $\begin{array}{l}\text { Jumlah daun yang terserang dan jumlah serangan pada masing-masing } \\
\text { daun yang terserang agak banyak }\end{array}$ & 2 \\
\hline Terserang berat & $\begin{array}{l}\text { Jumlah daun yang terserang dan jumlah serangan masing-masing daun } \\
\text { yang terserang banyak }\end{array}$ & 3 \\
\hline Mati & Seluruh daun rontok atau tidak ada tanda-tanda kehidupan & 4 \\
\hline
\end{tabular}

Teknik pengumpulan berasal dari data primer yang diperoleh dari hasil pengamatan langsung dan data sekunder merupakan data pendukung yang diperoleh dari instansi terkait pengamatan laboratorium.

Identifikasi hama dilakukan pada Laboratorium Silvikultur Fakultas Pertanian Universitas Pattimura Ambon. Penelitian dilaksanakan untuk mengidentifikasi hama yang ditemukan dengan menggunakan Buku Kunci Determinasi Serangga. Latumahina, (2008) dan Wattimena, Pelupessy, dan Selang (2016) bukan merupakan Buku Kunci Determinasi Serangga melainkan paper hasil penelitian. Buku Kunci Determinasi yang dipakai oleh Wattimena, Pelupessy, dan Selang (2016) disusun oleh Kalshoven, (1981), sedang pada Latumahina tidak menyebutkan Buku Kunci Serangga untuk identifikasi.

\section{E. Analisis data}

Analisis yang digunakan yaitu analisis kuantitatif.

\section{Intensitas serangan}

Untuk menghitung kerusakan pada tanaman jati maka digunakan rumus sebagai berikut :

IS $=\frac{\Sigma(\mathbf{n x v})}{\mathbf{Z} . \mathbf{N}} \times 100 \%$
Keterangan :

IS $\quad=$ Intensitas serangan

$\mathrm{n} \quad=$ Jumlah ranting per tanaman dari tiap kategori serangan

$\mathrm{v} \quad=$ Nilai skala dari tiap kategori serangan

$\mathrm{Z} \quad=$ Nilai skala dari kategori serangan tertinggi

$\mathrm{N}$ = Banyaknya ranting tanaman yang diamati

Untuk mengetahui intensitas kerusakan didasarkan pada kategori serangan, dapat dilihat pada Tabel 2.

Tabel 2. Penilaian intensitas kerusakan

\begin{tabular}{ccc}
\hline $\begin{array}{c}\text { Nilai } \\
\text { Skala }\end{array}$ & $\begin{array}{c}\text { Presentase } \\
\text { serangan }(\boldsymbol{\%})\end{array}$ & Kriteria \\
\hline 0 & 0 & Normal \\
1 & $1-25$ & Terserang ringan \\
2 & $26-50$ & Terserang sedang \\
3 & $51-75$ & Terserang berat \\
4 & $>76$ & Terserang sangat berat \\
\hline
\end{tabular}

\section{Luas serangan (LS)}

Untuk menghitung luas serangan hama digunakan rumus :

$$
P=\frac{a}{b} \mathrm{X} 100 \%
$$

Keterangan :

$\mathrm{P}=$ Luas serangan

a = Jumlah tanaman yang terserang

$\mathrm{b}=$ Jumlah tanaman yang diamati

Kategori serangan didasarkan pada kriteria penentuan kategori yang terdapat pada Tabel 3. 
Tabel 3 Kriteria penentuan kategori serangan

\begin{tabular}{ccc}
\hline $\begin{array}{c}\text { Nilai } \\
\text { skala }\end{array}$ & $\begin{array}{c}\text { Presentase } \\
\text { serangan }(\boldsymbol{\%})\end{array}$ & Kriteria \\
\hline 0 & 0 & Normal \\
1 & $1-25$ & Terserang ringan \\
2 & $26-50$ & Terserang sedang \\
3 & $51-75$ & Terserang berat \\
4 & $>76$ & Terserang sangat berat \\
\hline
\end{tabular}

\section{HASIL DAN PEMBAHASAN}

Serangga adalah bagian dari ekosistem

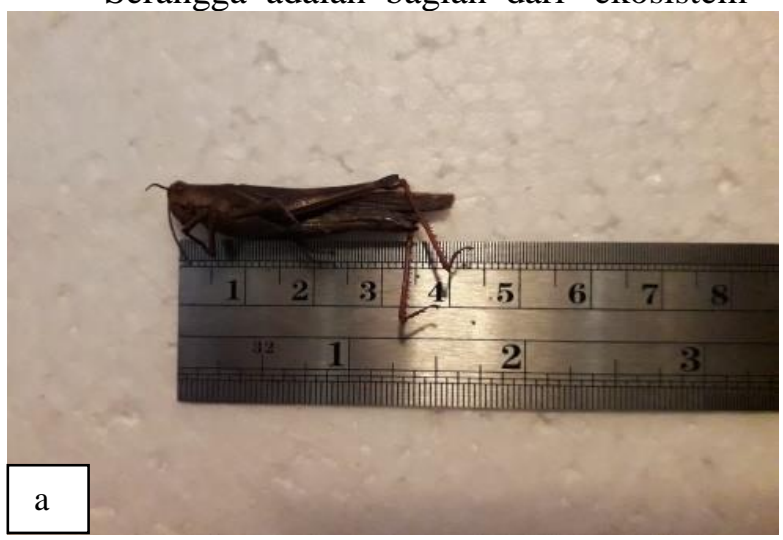

hutan, keberadaan serangga tidak selalu menimbulkan dampak negatif bagi pertumbuhan pohon. Serangan serangga daun pada umumnya tidak menyebabkan kematian pohon. Berdasarkan hasil penelitian, serangga hama yang ditemukan di areal Hutan Tanaman Rakyat di Negeri Hila, Kabupaten Maluku Tengah adalah dua jenis yaitu belalang kayu dan ulat daun jati. Hasil identifikasi kedua hama tersebut adalah Valanga nigricornis (Gambar 2) dan Hyblaea puera (Gambar 3).

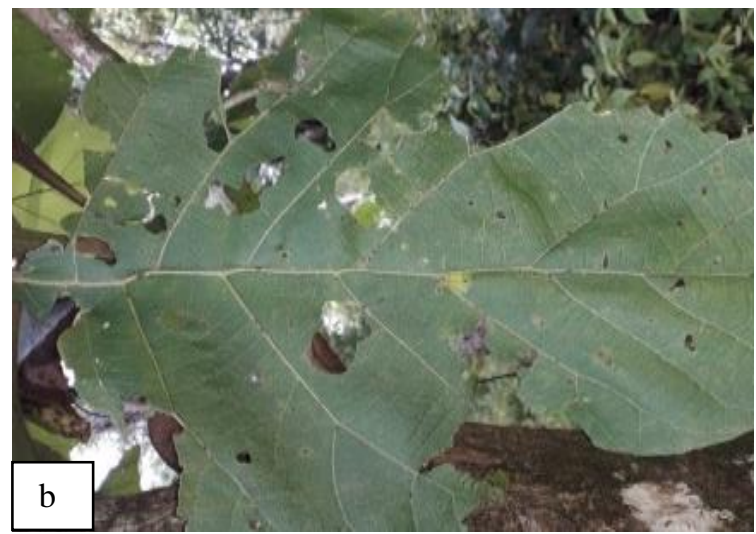

Gambar 2. ( a ) Valanga nigricornis ( b ) Bentuk kerusakan pada daun jati

$V$. nigricornis terdiri dari 3 bagian utama, yaitu kepala, dada (Thorax) dan perut (Abdomen) dan memiliki 6 (enam) kaki bersendi, 2 pasang sayap dan 2 antena. Belalang kayu berwarna cokelat termasuk golongan ordo Orthoptera dan famili Acrididae. Belalang kayu ini menyerang pohon jati dan berbagai pohon kayu-kayuan lainnya. Belalang kayu

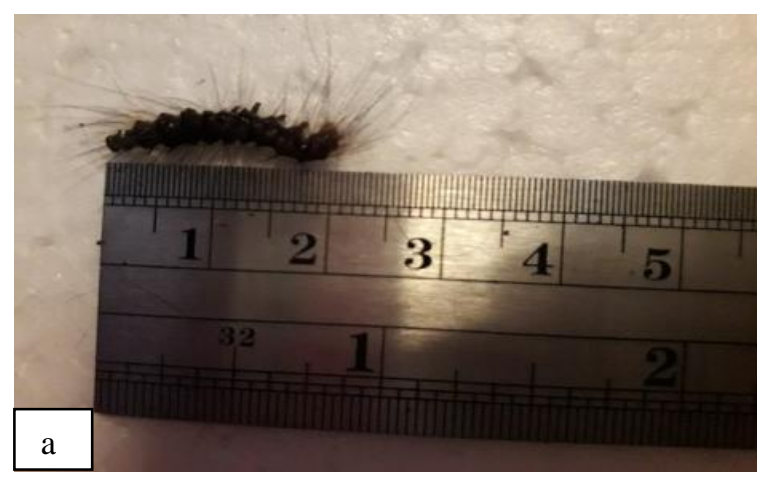

mempunyai panjang $4 \mathrm{~cm}$ sedangkan, gejala dan tanda yang ditimbulkan akibat dari serangan hama belalang kayu adalah rusaknya daun sebagian pada tanaman jati dan tanda yang ditimbulkannya yaitu terdapat daun di bagian tepinya tampak bekas gigitan terutama pada daun yang masih muda dan tua.

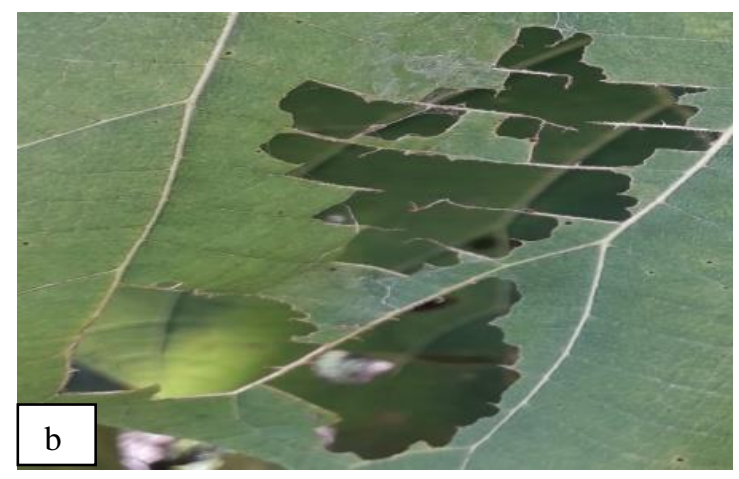

Gambar 3. ( a ) Ulat daun Jati ( b ) Bentuk kerusakan daun jati

H.puera termasuk dalam Ordo Lepidoptera Famili Noctuidae. Penyebarannya di India, Indonesia, Malaysia, Pakistan, Pulau Salomon, Afrika Selatan dan Afrika Timur.

(Nietschke et al., 2007). Selain menyeranng tanaman jati, juga menyerang tanaman lain. Hama ini biasanya menyerang pada awal musim penghujan, yaitu sekitar bulan November 
hingga Januari. Serangga hama ulat daun jati (Gambar 3a) yang ditemukan berukuran panjang $2 \mathrm{~cm}$ dan lebar tubuh $1,2 \mathrm{~cm}$ dengan bentuk serangan terjadinya lubang - lubang pada sebagian daun dan yang tertinggal hanya tulang daun akibatnya pertumbuhan tegakan melambat. Selain itu, membuat daun jati lama-

kelamaan akan berubah warna menjadi kuning, Gambar 3b.

\section{A. Intensitas serangan}

Intensitas serangan $V$. nigricornis dan H. puera pada Hutan Tanaman Rakyat (HTR) masuk dalam kategori terserang sedang, Tabel 4.

Tabel 4 . Intensitas kerusakan daun tanaman jati akibat serangan hama belalang daun jati dan hama ulat

\begin{tabular}{cccc}
\hline Blok & \multicolumn{3}{c}{ Jenis hama } \\
\cline { 2 - 4 } & Valanga nigricornis & Hyblaea puera & Kategori \\
\hline I & $30,93 \%$ & $31,91 \%$ & Terserang sedang \\
II & $29,70 \%$ & $27,13 \%$ & Terserang sedang \\
III & $31,54 \%$ & $31,44 \%$ & Terserang sedang \\
IV & $36,71 \%$ & $33,29 \%$ & Terserang sedang \\
V & $40,50 \%$ & $37,56 \%$ & Terserang sedang \\
\hline
\end{tabular}

Berdasarkan hasil penelitian, intensitas kerusakan daun tanaman jadi akibat serangan ulat daun dan belalang kayu berada pada kategori serangan sedang. Hal ini disebabkan karena faktor internal.

Faktor di dalam habitat itu sendiri yang mempengaruhi kehadiran dan perkembangan hama pada suatu lokasi adalah kemampuannya untuk berkembang biak. Kemampuan berkembang biak suatu serangga tergantung dari kecepatan berkembang biak dan perbandingan kelamin (sex ratio) antara serangga jantan dan betina (Dunn, Hofmann, Waters, \& Witchel, 2011). Hama dapat merusak tanaman dengan cara memakan, bertelur, berlindung, ataupun bersarang (Garden \& Cogreg, 2012). Besar kecilnya pengaruh kerusakan tanaman dan kehilangan hasil akibat serangan hama ditentukan beberapa faktor seperti tinggi rendahnya populasi hama yang hadir di pertanaman, bagian tanaman yang dirusak, tanggap tanaman terhadap serangan hama dan fase pertumbuhan tanaman/umur tanaman (Hariyanto et al., 2014).

Tabel 5. Luas serangan hama V.nigricornis

\begin{tabular}{ccccc}
\hline Blok & Jumlah tanaman & Yang terserang & Luas serangan & Kategori \\
\hline I & 47 & 11 & $23,40 \%$ & Terserang ringan \\
II & 48 & 16 & $33,33 \%$ & Terserang sedang \\
III & 47 & 16 & $34,04 \%$ & Terserang sedang \\
IV & 45 & 13 & $28,88 \%$ & Terserang sedang \\
V & 43 & 11 & $25,58 \%$ & Terserang singan \\
\hline
\end{tabular}

Berdasarkan hasil penelitian (Tabel 5), luas serangan hama $V$. nigricornis pada blok I dan III termasuk dalam kategori terserang ringan yaitu $23,40 \%$ dan $25,58 \%$, sedangkan blok II, III dan IV termasuk dalam kategori 
terserang sedang yaitu $33,33 \%, 34,04 \%$ dan $28,88 \%$.

$V$. nigricornis dan $H$. puera merupakan hama yang menyerang tanaman jati pada Hutan Tanaman Rakyat (HTR) di Negeri Hila, dengan luas serangan tergolong kategori rusak ringan hingga rusak sedang. Hal ini disebabkan karena, $V$. nigricornis merupakan salah satu serangga polifag, yang memiliki berbagai tanaman sebagai sumber makanannya. Selain tanaman jati, $V$. nigricornis juga memakan daun dari tanaman kopi, kakao, kelapa, mangga, kapuk, jagung, jarak, kapas, tebu, singkong. Lama hidup $V$. nigricornis dapat mencapai 3 sampai 5 bulan dengan keperidian mencapai 158 butir telur per betina (Pattiwael, 2018). Dengan demikian pengendalian terhadap $V$. nigricornis sangat sulit dilakukan (Hidayat \& Sari, 2014). Sedangkan $H$. puera menyerang pada awal musim penghujan. Ulat jati menggerogoti pinggiran daun, bahkan daun-daun yang terserang robek dan berlubang-lubang dimakan ulat. Bila ulat tidak banyak cukup diambil dan dimatikan (Wattimena, Latumahina, Puttileihalat, Sahetapy, \& Uruilal, 2020).

Tabel 6 Luas serangan hama H.puera

\begin{tabular}{ccccc}
\hline Blok & Jumlah tanaman & Yang terserang & Luas serangan & Kategori \\
\hline I & 47 & 14 & $29,78 \%$ & Terserang sedang \\
II & 48 & 14 & $29,16 \%$ & Terserang sedang \\
III & 47 & 6 & $12,76 \%$ & Terserang ringan \\
IV & 45 & 11 & $24,44 \%$ & Terserang ringan \\
V & 43 & 9 & $20,93 \%$ & Terserang ringan \\
\hline
\end{tabular}

Berdasarkan hasil penelitian Tabel 6, luas serangan hama $H$. puera pada blok I dan II termasuk dalam kategori terserang sedang yaitu: $29,78 \%$ dan $29,16 \%$, sedangkan blok III, IV dan $\mathrm{V}$ termasuk dalam kategori terserang ringan.

Hasil penelitian menunjukkan bahwa luas serangan yang diakibatkan oleh Hama $V$. nigricornis seluas $29,94 \%$ dapat dikategorikan sebagai rusak sedang. Hama $V$. nigricornis menuntut hidup di semak-semak dan pepohonan. Belalang ini dapat melakukan reproduksi dengan cepat dan melakukan migrasi secara besar-besaran. Nimfa dan imago memakan daun dan merupakan serangga yang polifag (menyerang berbagai jenis tanaman. Sedangkan menurut Antonacci et al. (2017) bahwa belalang merupakan serangga herbivora yang terkenal sebagai serangga dengan kemampuan melompat melampaui jarak hingga 20 kali panjang tubuhnya. Dengan demikian hama $V$. nigricornis kemungkinan menyebabkan kerusakan lebih besar (Anggraeni \& Mindawati, 2011).

Hama $H$. puera seluas $23,41 \%$ termasuk dalam kategori rusak ringan. Hal ini disebabkan karena sumber pakan yang tersedia tidak disukai oleh hama tersebut. Menurut Herdiana (2010) umumnya masing-masing jenis ulat berspesialisasi memakan daun dari jenis-jenis tumbuhan yang tertentu saja, juga ditentukan oleh ketersediaan tumbuhan yang menjadi inang dari ulatnya.

Intensitas serangan $V$. nigricornis dan $H$. puera tidak berpengaruh besar terhadap pertumbuhan tanaman jati dan secara ekonomis tidak menimbulkan dampak yang besar. Hal ini disebabkan karena intensitas serangan kedua jenis serangga hama ini masih masuk dalam kategori rusak sedang $(33,88 \%$ dan 32,27\%).

Beberapa faktor yang diduga turut berpengaruh terhadap kehadiran dua jenis hama dalam kawasan HTR yakni faktor lingkungan, 
jumlah populasi tanaman (makanan) dan jumlah populasi hama (kepadatan) serta faktor kompetisi antar spesies. Jumlah populasi tanaman turut berpengaruh terhadap jumlah makanan sehingga sangat mempengaruhi keadaan suatu spesies hama di lingkungan. Hal tersebut sejalan dengan pendapat dari Herdiana (2010) bahwa makanan merupakan unsur utama dan sangat menentukan bagi kelangsungan hidup setiap spesies hama. Kualitas dan kuantitas makanan dapat pula mempengaruhi kemampuan berkembang biak hama yang menyerangnya. Apabila bagian tanaman yang disukai terdapat dalam jumlah banyak maka kemampuan berkembang biak hama tersebut semakin tinggi (Wattimena et al., 2020).

\section{KESIMPULAN}

Kerusakan tanaman jati dalam Hutan Tanaman Rakyat (HTR) disebabkan oleh serangga hama $V$. nigricornis dan $H$. puera dengan intensitas kerusakan tergolong dalam kategori terserang sedang. Luas serangan serangga hama $V$. nigricornis adalah 29,58\% tergolong dalam kategori terserang sedang dan $H$. puera adalah $23,41 \%$ tergolong dalam kategori terserang ringan.

\section{UCAPAN TERIMA KASIH}

Penulis mengucapkan terima kasih kepada pimpinan Laboratorium Silvikultur Fakultas Pertanian Universitas Pattimura Ambon yang telah mengijinkan penggunaan laboratorium untuk pengolahan data penelitian.

\section{DAFTAR PUSTAKA}

Antonacci, R., Tritto, P., Cappucci, U., Fanti, L., Piacentini, L., \& Berloco, M. (2017). Drosophilidae monitoring in apulia (Italy) reveals Drosophila suzukii as one of the four most abundant species. Bulletin of Insectology, 70(1), 139-146.

Dunn, A. M., Hofmann, O. S., Waters, B., \& Witchel, E. (2011). Cloaking malware with the trusted platform module. Proceedings of the 20th USENIX Security Symposium.
Garden, E., \& Cogreg, B. (2012). Nusantara di Kebun Percobaan Universitas Nusa Bangsa Cogreg , Bogor Inventory of Plant Pest Teak Superior Nusantara

Hariyanto, T., Jumani, \& Heni, E. (2014). Identifikasi Hama dan Penyakit Shorea Leprosula Miq di Taman Nasional Kutai Resort Sangkima Kabupaten Kutai Timur Provinsi Kalimantan Timur. Agrifor, 9(2), 175-184.

Herdiana, N. (2010). Potensi Serangan Hama Tanaman Jati Rakyat Dan Upaya Pengendaliannya Di Rumpin, Bogor. Jurnal Penelitian Hutan Tanaman, 7(4), 201-209. http://doi.org/10.20886/jpht.2010.7.4.201209

Hidayat, R., \& Sari, I. (2014). Hama Pada Tegakan Jati (Tectona grandis L.f ) di Desa Talaga Kecamatan Dampelas Kabupaten Donggala, 2(1), 17-23.

Latumahina, F. (2008). Diversitas Serangga di Sekitar Sub Daerah Aliran Sungai Wai Batu Gajah Kota Ambon Propinsi Maluku. Jurnal Agroforestri, 2(Maret).

Latumahina, F., Borovanska, M., Musyafa, Sumardi, Putra, N. S., \& Janda, M. (2015). Ants of Ambon Island - Diversity survey and checklist. ZooKeys, 472, 43-57. http://doi.org/10.3897/zookeys.472.8441

Latumahina, F., \& Susetya, N. (2015). Respon Semut Terhadap Kerusakan Aantropogenik Dalam Hutan Lindung Sirimau Ambon (Ants Response to Damage Anthropogenic in Sirimau Forest Ambon ) Program Doktor Ilmu Kehutanan, Universitas Gajah Mada Yogyakarta, Penulis korespondensi . No Tel : 0911-3621. Jurnal Manusia Dan Lingkungan, 22(2), 169-178. http://doi.org/10.22146/jml.18739

Nietschke, B. S., Magarey, R. D., Borchert, D. M., Calvin, D. D., \& Jones, E. (2007). A developmental database to support insect phenology models. Crop Protection, 26(9), 1444-1448. http://doi.org/10.1016/j.cropro.2006.12.006

Pattiwael, M. (2018). Analisis Tingkat Kerusakan Tanaman Jati (Tectona grandis L.f) Akibat Serangan Hama di Kelurahan Klamalu Distrik Mariat Kabupaten Sorong. Daun: Jurnal Ilmiah Pertanian Dan Kehutanan, 5(2), 89-96. http://doi.org/10.33084/daun.v5i2.465

Tjoa, M., Kastanya, A., Iskar, Latumahina, F., \& Aponno, H. (2020). Certainty in the management of customary community forest 
Vol. 13 No. 1, Juni 2019, p. 1 - 8

land in Western Seram District, Maluku. Test Engineering and Management, 82(13838), 13838-13844.

Wattimena, C. M. A., Latumahina, F., Puttileihalat, M. M. S., Sahetapy, B., \& Uruilal, C. (2020). A combination of soursop and lemongrass leaves extract as a vegetable biopesticide.
Test Engineering and Management, 83(23), 23-29.

Wattimena, C. M. A., Pelupessy, L., \& Selang, S. (2016). Identifikasi Jenis Hama Tanaman Damar (Agathis alba) di Hutan Lindung Sirimau Kota Ambon Provinsi Maluku. Agrologia, 5(2), 95-100. http://doi.org/10.30598/a.v5i2.187 